\title{
Correction to: a model study of present-day Hall-effect circulators
}

\author{
B. Placke ${ }^{1 *}$, S. Bosco ${ }^{1,2}$ (D) and D.P. DiVincenzo $0^{1,2,3}$
}

"Correspondence:

benedikt.placke@rwth-aachen.de 'Institute for Quantum Information, RWTH Achen University, Aachen, Germany

Full list of author information is available at the end of the article
Since the publication of the original article [1], one of the authors noticed a typographical error to equations (11a) and (11b) in their published article [1]. The correct versions of (11a) and (11b) are included in this Correction article.

$$
\begin{gathered}
C_{m} \omega_{m}=\frac{1}{\sqrt{Z_{0} R_{c}}} \sqrt{1-\frac{Z_{0}}{R_{c}}}, \\
L_{m} \omega_{m}=\sqrt{Z_{0} R_{c}} \sqrt{1-\frac{Z_{0}}{R_{c}}}
\end{gathered}
$$

\section{Author details}

${ }^{1}$ Institute for Quantum Information, RWTH Achen University, Aachen, Germany. ${ }^{2}$ Jülich-Aachen Research Alliance (JARA), Fundamentals of Future Information Technologiesh, Jülich, Germany. ${ }^{3}$ Peter Grünberg Institute, Theoretical

Nanoelectronics, Forschungszentrum Jülich, Jülich, Germany.

\section{Publisher's Note}

Springer Nature remains neutral with regard to jurisdictional claims in published maps and institutional affiliations.

Received: 24 January 2018 Accepted: 24 January 2018 Published online: 31 January 2018

\section{References}

1. Placke B, Bosco S, DiVincenzo DP. A model study of present-day Hall-effect circulators. EPJ Quantum Technol. 2017;4:5. https://doi.org/10.1140/epjqt/s40507-017-0057-9. (http://creativecommons.org/licenses/by/4.0/), which permits unrestricted use, distribution, and reproduction in any medium, provided you give appropriate credit to the original author(s) and the source, provide a link to the Creative Commons license, and indicate if changes were made. 